\title{
LOW-THRESHOLD SERVICES FOR PROBLEM DRUG USERS IN HUNGARY
}

\author{
Katalin Melles ${ }^{1}$, Ferenc Márványkövi ${ }^{1}$, Jozsef Rácz ${ }^{1,2}$ \\ ${ }^{1}$ Research Institute on Drug Studies, Eötvös University, Budapest \\ ${ }^{2}$ Institute for Psychology, Hungarian Academy of Sciences, Budapest
}

\section{SUMMARY}

Objectives: The main objective of this study was to explore how harm reduction (HR) approach and low-threshold approach are realised at low-threshold services (LTSs) in Hungary in comparison with the guidelines presented in different policy papers (European Union drugs strategies) and national regulations.

Materials and methods: Hungarian LTSs were investigated: 29 organisations out of 44 ( $66 \%$ return rate) were reached with questionnaires and 40 LTS workers were interviewed.

Results: The LTSs have difficulties reaching their target group, distributing sufficient sterile syringes and interpreting the concept of 'low-threshold' and HR, sometimes defining them as a transient stage to abstinence-based treatment.

Conclusion: The study results suggest that Hungarian LTSs need to be re-orientated toward more emphasis on health-related issues.

Key words: drug abuse, harm reduction, Hungary, low-threshold service

Address for correspondence: J. Rácz, Institute for Psychology of the Hungarian Academy of Sciences, Victor Hugo utca 18-22, Budapest - 1132, Hungary. E-mail: raczj@mtapi.hu

\section{INTRODUCTION}

The UNAIDS (Joint United Nations Programme on HIV/ AIDS) (1), the European Union (2) as well as Hungarian drug policy documents (3) emphasize the importance of harm reduction (HR) and low-threshold (LT) services for drug users. The HR approach and the services provided by low-threshold agencies (LTS) (4) contribute to the reduction of social and individual harms caused by drug abuse $(5,6)$. Transitional countries (statecontrolled countries developing into market economy) display particular drug and HIV-related problems $(7,8)$. Therefore, it is quite useful to view how a transitional country makes an attempt to apply HR.

The most important client population of LTSs is 'problem drug users'. Problem of drug use (PDU) is defined as 'injecting drug use or long duration/regular use of opiates, cocaine and/or amphetamines' by the European Monitoring Centre for Drugs and Drug Addiction (EMCDDA) $(9,10)$. According to the Annual Reports $(11,12)$, the ratio of problem drug users to the general population is $2-10 / 1000$ inhabitants in the 15-64 age group, with significant differences among countries as well as within them. The injecting drug user (IDU) prevalence is about $1-6 / 1000$ in the same age group. According to the EMCDDA reports, the available data show that the ratio of needles (from needle and syringe programs, NSP) distributed to IDUs vary from 25 needles/IDU/year (France and Portugal) to 76 (Austria) or 162 (Czech Republic) $(11,12)$.

According to current available data, Hungary (10 million inhabitants) has one of the lowest drug abuse prevalence rates among the EU member states $(12,13)$. The HIV infection ratio among IDUs was 1\% in the period between 1997-2004 (14). However, between 1997 and 2002, the proportion of hepatitis C (HCV) infected IDUs treated in hospitals rose from $16 \%$ to $30 \%$ (15). While in the new EU member states drug-related death increased between 1996 and 2003, Hungary is experiencing a decreasing rate with drug-related annual death figure dropping from 52 to 32 in the same period (12). The Hungarian National Drug Strategy (3) as well as other regulations (16) make a reference to the set-up of low-threshold agencies as well as HR services (17). The main objective of this study was to explore how HR approach and lowthreshold method are realised at LTSs in Hungary in comparison with the guidelines to be found in different policy papers (2) and national regulations $(3,16)$.

\section{MATERIALS AND METHODS}

\section{Sampling Procedure and Sample Description}

To select agencies, a directory called 'Droginfó' (18) that includes contact details of all Hungarian LTSs was used. To obtain a representative sample, all organisations defining themselves as 'low-threshold agencies' were selected from the directory. Then a sub-sample was made by omitting incorrectly categorised agencies (abstinence-based services). Of the 62 agencies selected this way, 4 had ceased operations before the survey, 14 did not return the questionnaire as they could not interpret the questions as they turned out to be agencies providing services to target groups other than drug users. Thus the sample was reduced to 44 organisations from all parts of Hungary. 29 organisations returned the questionnaire finally, which represents a $66 \%$ response rate. The 
LTSs returning the questionnaire cover the whole of the country geographically. Semi-structured interviews with the drug policy expert of the Hungarian Civil Liberties Union and 40 employees including programme leaders, social workers, psychologists, addiction consultants and medical staff at Hungarian syringe exchange programmes (SEP) were also conducted. The 10 agencies selected for the survey fully represent the Hungarian NSPs (3 located in Budapest, 7 outside Budapest).

\section{Questionnaire Design}

The agency inventory questionnaire was developed partly based on the EMCDDA's data collection tools used for national reports and in consultation with the project management, a programme leader at a Budapest-based LTS, an expert on social issues from the Ministry of Social Affairs and the Hungarian National Focal Point. The questionnaire contained 70 questions in total and focussed on (1) management details, (2) services, (3) referrals, (4) quality insurance, (5) methodology used by the agency, (6) client-related data, (7) service evaluation. The semistructured interviews made with organisation managers and LTS staff followed the same structure but contained more qualitative questions. Both types of tools were pilot tested by staff working at LTSs in Budapest.

\section{Data Collection and Analysis}

Data collection took place in the period between March and June 2005. The agency inventory questionnaire was a 90-minute self-administered questionnaire, which was mailed to managers of LTSs. Then follow-up phone calls were made to ensure the questionnaires had been received. Then the questionnaires were returned to the research centre. The semi-structured interviews conducted by staff members and organisation managers were interviewer administered and lasted approximately 90 minutes.

\section{RESULTS AND DISCUSSION}

\section{Access to Target Group}

Only 14 of the 29 LTSs could report on how many individual clients they serviced in 2004. The lowest figure was 3, while the highest amounted to 1,521. According to two studies on the volume of problem drug users $(19,20)^{1}$, the number of problem drug users was estimated at 24,204 in Hungary in 2005, while the volume of injecting users only was estimated at 3,900 in Hungary in 2005. In comparison with the figures provided by our respondents, we may conclude that LTSs have low access rate to problem drug users, reaching only $6.1 \%$ of the user population at the maximum. It also seems that the national health treatment system is more effective in reaching hidden problem drug users. According to national data from 2004 (21), of all the 14,165 treated drug users, $14.4 \%$ were opiate, while $8.6 \%$ amphetamine users. This can be explained by the fact that the national health treatment system for drug users is more available at regional level. As for the availability of LT services, there are considerable differences among regions. Yet, regarding NSP coverage, Hungary provides syringe exchange nationwide compared to other EU countries such as Ireland, Greece, Italy and Sweden $(11,12)$.

\section{Low-threshold Concept}

On the basis of the study regarding HR concepts, it seems that LTSs had difficulties defining and interpreting 'low-threshold'. Few agencies have clear mission statement, policy and theoretical concept. As a result, "low-threshold" is often interpreted as a pure transition towards abstinence-based treatment. It may be explained by the fact that although a number of Hungarian regulations formulate and advocate HR and low-threshold services, apart from the NSP protocol (as well as the methadone substitution which is not dealt with in this study), there is no other professional protocol for HR in Hungary. The engine of slow spreading of HR services is the public administration and the Social Law (16), ${ }^{2}$ although it contains a HR definition and the opportunity and the possibility to organize such services.

Table 1. National needle and syringe exchange data (2004)

\begin{tabular}{|l|c|c|c|}
\hline & Budapest & $\begin{array}{c}\text { Outside } \\
\text { Budapest }\end{array}$ & Total \\
\hline $\begin{array}{l}\text { Needles and syringes } \\
\text { distributed }\end{array}$ & 50990 & $* 22925-27925$ & $73915-78915$ \\
\hline $\begin{array}{l}\text { Needles and syringes } \\
\text { returned }\end{array}$ & 31440 & $13120-\star 16870$ & $44038-48038$ \\
\hline $\begin{array}{l}\text { Needles and syringes } \\
\text { collected from public areas }\end{array}$ & 1993 & 25 & 2015 \\
\hline
\end{tabular}

*the figure contains estimated numbers as well

**the figure contains estimated numbers as well as lack of data

Our study has found that the number of sterile syringes distributed by NSPs to problem drug users ranged between 73,915 and 78,915 nationwide in 2004 Table 1 . In comparison with the estimated number of problem drug users and injectors for 2005 $(19,20)$, the number of sterile syringes distributed is 3-3.3 per problem drug user per year, while this figure is 19-20 per injecting user per year. In comparison with other EU member states (Czech Republic, Finland, Poland) $(9,10,22)$, the Hungarian figures are rather low. This may suggest that the Hungarian problem drug users/injecting users are a seriously underserved population. In addition, the number of agencies conducting HIV, hepatitis B and $\mathrm{C}(\mathrm{HBV}, \mathrm{HCV})$ tests was four and there were two agencies that reported conducting all the five tests (including tuberculosis and syphilis). These two facts (i.e. low syringe distribution figures and limited availability for blood born infections testing), however, may also be explained by the low HIV and HCV figures seen among intravenous users in Hungary $(15,23)$.

\section{CONCLUSION}

Our results indicate that Hungarian LTSs are not effective enough in accessing their target population (problem drug users). This may be attributed to the fact that their number is not sufficient and HR approach as well as the institutional policy is not clarified precisely. In order to improve the availability of LT services, the establishment of the more effective organisational forms and user involvement are needed. The striking absence of health-related services in Hungarian LTSs can be explained by the fact that LT services are considered to be part of social services. 
Our current and former (24) results suggest that LTSs need to be re-orientated. This implies that the increase of specialised health services targeting problem drug users and the advocacy of the HR approach are needed. This can be done within the framework of the national drug policy, which needs to be reviewed.

\section{LIMITATIONS}

Due to the lack of standardised European agency inventory on LTSs, as well as the less reliable data on the prevalence of problem drug use and syringe exchange at the European level, the interpretation of our study in the European context has to be made with caution.

\section{Acknowledgements}

The study was financed by the Hungarian National Drug Focal Point (REITOX) and the Ministry of Child, Family, Social Affairs and Equal Opportunities (KAB).

\section{REFERENCES}

1. Burrows D, editor. High coverage sites: HIV prevention among injecting drug users in transitional and developing countries: case studies. Geneva: UNAIDS; 2006.

2. European Union drugs strategy (2000-2004). 12555/3/99 REV 3, Cordrogue 64. Brussels: Council of the European Union; 1999.

3. National drug strategy for the reduction of drug problems. Budapest: Ministry of Youth and Sports Affairs; 2000. (In Hungarian.)

4. Hedrich D. Data-collection at low-threshold services for drug users: tools, quality and coverage. Lisbon, 9-10 December 2004, EMCDDA [final draft meeting report]. Luxembourg: Office for Official Publications of the European Communities; 2004.

5. Marlatt AG, editor. Harm reduction: pragmatic strategies for managing high-risk behaviors. New York: The Guilford Press; 1998

6. Reid RJ. Harm reduction and injection drug use: pragmatic lessons from a public health model. Health Soc Work. 2002 Aug,27(3):223-6.

7. Donoghoe MC, Lazarus JV, Matic S. HIV/AIDS in the transitional countries of Eastern Europe and Central Asia. Clin Med. 2005 SepOct;5(5):487-90.

8. European Monitoring Centre for Drugs and Drug Addiction (EMCDDA). The state of the drugs problem in the acceding and candidate countries to the European Union. Luxembourg: Office for Official Publications of the European Communities; 2003.

9. Kraus L, Augustin R, Frischer M, Kümmler P, Uhl A, Wiessing L. Estimating prevalence of problem drug use at national level in countries of the European Union and Norway. Addiction. 2003 Apr;98(4):471-85.
10. Smit F, Toet J, van Oers H, Wiessing L. Estimating local and national problem drug use prevalence from demographics. Addict Res Theory. 2003 Dec;11(6):401-13.

11. European Monitoring Centre for Drugs and Drug Addiction (EMCDDA). Annual Report 2003: the state of the drugs problem in the European Union and Norway. Luxembourg: Office for Official Publications of the European Communities; 2003.

12. European Monitoring Centre for Drugs and Drug Addiction (EMCDDA). Annual Report 2005: the state of the drugs problem in the European Union and Norway. Luxembourg: Office for Official Publications of the European Communities; 2005.

13. Hibell B, Andersson B, Bjarnason T, et al. The ESPAD Report 2003: alcohol and other drug use among students in 35 European Countries. Strasbourg: The Swedish Council for Information on Alcohol and Other Drugs (CAN) and Council of Europe Pompidou Group; 2004.

14. European Centre for the Epidemiological Monitoring of AIDS. HIV/AIDS Surveillance in Europe. End-year report 2004, No.71. Saint Maurice: Institut de Veille Sanitaire; 2005.

15. Bánhegyi D, Ujhelyi E, Zacher G. The infection risk of injecting drug use. In: Topolánszky Á, editor. Hungarian national report on drug use. Budapest: GYISM; 2002. p. 81-8. (In Hungarian.)

16. Social Law (No. 3/1993 modification is in operation from January 1 2007). (In Hungarian.)

17. Hungarian Civil Liberties Union [homepage on the Internet]. HCLU about harm reduction oriented drug policy. Budapest: TASZ; 1998. [cited 2006 Aug 2]. Available from: http://www.tasz.hu/index.php?op=contentlist2\& catalog id $=1625$

18. Kály-Kullai K, editor. Collection of drug services. Budapest: "Island" Drug Information Foundation; 2003. (In Hungarian.)

19. Nyírády A, Porkoláb L. Problem drug use. In: Nyírádi A, Felvinczi K, Gábor E, editors. Hungarian national report on drug use. Budapest: Ministry of Youth, Family Affairs and Equal Opportunities; 2004. p. 53-61. (In Hungarian.)

20. Elekes Zs, Nyírádi A. Estimating the prevalence of problem drug use with the capture-recapture method. Addiktológia (Addictologia Hungarica). In press 2007. (In Hungarian.)

21. National Statistical Programme. National report on drug situation in Hungary. Budapest: National Institute for Psychiatry and Neurology; 2004. (In Hungarian.)

22. European Monitoring Centre for Drugs and Drug Addiction (EMCDDA). National prevalence estimates of problem drug use in the European Union, 1995-2000. Final Report CT.00.RTX.23 - Data update for EMCDDA 2003 Annual Report. Lisbon: EMCDDA; 2003.

23. Csohán Á, Kaszás K, Lendvai Gy. Prevalence of infectious diseases among injecting drug users [unpublished research report]. Budapest: National Centre of Epidemiology; 2006. (In Hungarian.)

24. Gyarmathy VA, Rácz J, Neaigus A, Ujhelyi E. The urgent need for HIV and hepatitis prevention in drug treatment programs in Hungary. AIDS Educ Prev. 2004 Jun;16(3):276-87.

Received August 2, 2006 Received and accepted in revised form February 13, 2007 